\title{
ULTRAESTRUCTURA DEL GERMARIO DE DACTYLOPIUS COCCUS COSTA, 1829 (HEMIPTERA: COCCOIDEA: DACTYLOPIIDAE)
}

\author{
ArTuro RAMÍREZ-CRUZ \\ Centro de Educación Continua, Unidad Morelia. Instituto Politécnico Nacional. 58190. Morelia, \\ Michoacán, México.<aramirezc@ipn.mx>
}

Ramírez-Cruz, A. 2012. Ultraestructura del germario de Dactylopius coccus Costa, 1829 (Hemiptera: Coccoidea: Dactylopiidae). Acta Zoológica Mexicana (n. s.), 28(3): 586-593.

RESUMEN. Se realizó la descripción ultraestructural del germario de hembras adultas de Dactylopius coccus Costa, 1829, mediante microscopía electrónica de transmisión. El germario está rodeado por una cubierta epitelial interna y por una túnica propia. Contiene además grandes células nutricias con núcleos de forma irregular, cuya membrana estaba perforada con gran cantidad de poros nucleares, observándose además uno o más nucléolos. Por otra parte, su citoplasma contenía una gran cantidad de ribosomas y mitocondrias, pero escaso retículo endoplásmico rugoso. No se observaron retículo endoplásmico liso ni complejos de Golgi. En las células nutricias de las hembras de dos días se observaron bacterias, aparentemente simbiontes, quedando por determinar su posible función en la fisiología de los ovarios. En algunas células nutricias de las hembras de diez días se observaron pequeños grupos de laminillas anulares, las cuales podrían estar relacionadas con un proceso degenerativo de dichas células. Los cordones tróficos se conformaron por una gran cantidad de microtúbulos y entre ellos se observaron numerosos ribosomas y numerosas mitocondrias, muchas de ellas de forma alargada.

Palabras clave: Dactylopius coccus, germario, ultraestructura.

Ramírez-Cruz, A. 2012. Ultrastructure of the tropharium of Dactylopius coccus Costa, 1829 (Hemiptera: Coccoidea: Dactylopiidae). Acta Zoológica Mexicana (n. s.), 28(3): 586-593.

ABSTRACT. An ultrastructural description of adult females tropharium of Dactylopius coccus Costa, 1829 , by electron microscopy transmission was realized. The tropharium is surrounded by an inner epithelial sheath and by a tunica propria. Furthermore, it contains large nurse cells with irregular-shaped nuclei and their nuclear membrane is abundantly perforated with nuclear pores; further one or more nucleoli were seen. Moreover their cytoplasm contained large numbers of ribosomes and mitochondria, but scarce rough endoplasmic reticulum. Neither smooth endoplasmic reticulum nor Golgi complex were observed. In the nurse cells of the females of two days-old, bacteria apparently symbionts were found, but their possible role in the ovarian physiology is unknown. Some nurse cells of females at ten days-old, had small groups of annular lamellae, which could be related with a degenerative process in these cells. The trophic cords were made of great number of microtubules and between them numerous ribosomes and mitochondria, many of them of elongated form.

Key words: Dactylopius coccus, tropharium, ultrastructure.

Recibido: 08/05/2012; aceptado: 22/06/2012. 


\section{INTRODUCCIÓN}

Las hembras de la superfamilia Coccoidea poseen ovarios con ovariolas de tipo telotrófico. Aunque éstas no presentan filamento terminal, en ellas se pueden distinguir claramente el germario y el vitelario, este último conectándose a un corto pedicelo. En el interior del germario existe un determinado número de células nutricias, las cuales se conectan con los ovocitos del vitelario a través de proyecciones citoplasmáticas denominadas cordones tróficos (King \& Büning 1985; Szklarzewicz 1998a; Szklarzewicz 1998b). Las células nutricias (generalmente poliploides) son la fuente tanto de ribosomas como de mitocondrias, siendo ambos organelos transportados hacia los ovocitos en crecimiento a través de los cordones tróficos (King \& Büning 1985). Una vez que los ovocitos han alcanzado cierto grado de madurez, los cordones tróficos finalmente degeneran (Engelmann 1970; King \& Büning 1985).

Dentro de esta superfamilia, la familia Dactylopiidae es una de las más importantes, ya que en ella se encuentra la grana cochinilla Dactylopius coccus Costa, 1829, especie de gran importancia económica pues de ella se obtiene el colorante rojo ácido carmínico, el cual se usa con varios fines industriales (Vigueras \& Portillo 2001).

Estudios previos de cultivo in vitro, han vinculado a los ovarios de D. coccus con la producción del ácido carmínico (Cortés et al. 2005). En lo referente a las características morfofisiológicas de sus ovarios, se sabe entre otros aspectos, que las ovariolas en esta especie son de tipo telotrófico, que maduran de manera asincrónica y que sus germarios presentan entre seis y siete células nutricias, además de que cada ovariola contiene un solo ovocito el cual entra en maduración (Ramírez-Cruz et al. 2008).

Debido a la importancia económica de $D$. coccus y a la muy escasa información sobre la estructura de los ovarios en esta especie, el objetivo de este estudio fue realizar una descripción ultraestructural del germario de la hembra adulta con la finalidad de profundizar en el conocimiento de la estructura de sus ovarios. Esta información ayudará a una mejor comprensión de la morfofisiología de estos órganos en esta especie.

\section{MATERIAL Y MÉTODOS}

Las hembras adultas de $D$. coccus se obtuvieron mediante la infestación de pencas de nopal (Opuntia ficus-indica (L.) Mill. var. Atlixco) de alrededor de dos años de edad, usando para ello bolsas de tela de tul de $3 \times 3 \mathrm{~cm}$ (Aldama $\&$ Llanderal 2003). Las pencas ya infestadas se mantuvieron verticales mediante hilos de rafia separados $6 \mathrm{~cm}$ uno de otro, dentro de peceras de vidrio de $0.50 \times 0.26 \times 0.30 \mathrm{~m}$. Los insectos se mantuvieron a una temperatura promedio de $21^{\circ} \mathrm{C}$ y $45 \%$ de humedad relativa en promedio.

Se utilizaron hembras adultas de 2, 4, 5, 7 y 10 días de edad, con dos o tres individuos para cada edad. Para determinar las características ultraestructurales, los ovarios se obtuvieron mediante disección en solución de Ringer para insectos (Martínez 
1999), se fijaron en glutaraldehido al $2.5 \%$ y se postfijaron en tetraóxido de osmio al $1 \%$, se deshidrataron y se incluyeron en resina Epon 812 . Se realizaron cortes finos de $70 \mathrm{~nm}$ de espesor, los cuales se contrastaron con acetato de uranilo y citrato de plomo. Finalmente se observaron en un microscopio electrónico de transmisión Jeol JEM-1010.

\section{RESULTADOS}

El germario de cada ovariola de $D$. coccus es de forma casi esférica y externamente está rodeado por un par de cubiertas, de las cuales la más externa es la túnica propia (Figs. 1A, 1B), de naturaleza completamente acelular y con un espesor aproximado de $0.1 \mu \mathrm{m}$. Inmediatamente debajo de la túnica propia se encuentra la cubierta epitelial interna de aproximadamente $3.5 \mu \mathrm{m}$ de espesor (Fig. 1A), constituida por células planas con núcleos ovalados y la heterocromatina compactada en pequeños grumos en el centro del núcleo; su citoplasma es escaso en retículo endoplásmico rugoso y en mitocondrias, pero abundante en ribosomas (Figs. 1A, 1C).

Las células nutricias en $D$. coccus presentaron grandes núcleos, principalmente de forma irregular (Figs. 1A, 1C). Además en la membrana nuclear de dichas células, se observó una alta densidad de poros nucleares distribuidos de manera regular (Fig. 1D). La heterocromatina de estas células en $D$. coccus adquirió la forma tanto de pequeños gránulos dispersos en todo el citoplasma (Fig. 1D), como de grandes paquetes heterocromáticos (Fig. 1C). En estas células se apreciaron uno o más nucléolos por célula nutricia (Fig. 1E), gran cantidad de ribosomas libres y algunos asociados al retículo endoplásmico rugoso, el cual fue muy escaso y formado de cisternas simples (Fig. 2A).

Del mismo modo, las células nutricias tuvieron gran abundancia de mitocondrias, muchas de ellas de forma alargada (Figs. 1A, 2B). A diferencia de la abundancia en ribosomas y de mitocondrias, no se observó retículo endoplásmico liso ni complejos de Golgi en las células nutricias.

En el citoplasma de las células nutricias se apreciaron ciertos grupos de bacterias endosimbiontes (algunas de ellas dividiéndose), cuya longitud fue de aproximadamente $1.4 \mu \mathrm{m}$, que estaban rodeadas de una membrana perisimbiótica (Fig. 2C).

En el citoplasma de las células nutricias de las ovariolas de las hembras de D. coccus de 10 días de edad, se observaron escasos grupos de laminillas anulares formadas por cinco y ocho cisternas de laminillas cortas, apreciándose entre ellas escaso material electrodenso (Fig. 2D), aparentemente no asociadas a ningún tipo de organelo, tal como el núcleo o el retículo endoplásmico rugoso.

Ultraestructuralmente el cordón trófico de $D$. coccus es completamente acelular, y está formado en su interior principalmente por una gran cantidad de microtúbulos acomodados paralelamente en toda su longitud. Entremezclados entre los microtúbulos fue posible apreciar abundantes mitocondrias en toda la longitud del cordón tró- 
Figura 1. Micrografías electrónicas del germario de D. coccus. A. Cubiertas del germario observándose una célula de la cubierta epitelial interna (ce) y la túnica propia (flecha corta). La heterocromatina de la célula epitelial agrupada en pequeños grumos (flecha larga). B. Célula de la cubierta epitelial interna observándose la túnica propia

(flecha). C. Célula de la cubierta epitelial interna (ce) con escaso retículo endoplásmico (círculo) y abundantes ribosomas (granulaciones pequeñas). La heterocromatina de la célula nutricia (flecha) formando grandes paquetes. D. Núcleo de una célula nutricia observándose los poros nucleares cortados transversalmente (flechas). E. Núcleo de una célula nutricia observándose nucléolos (nu). c, citoplasma; ce, célula epitelial; cn, célula nutricia; $\mathrm{m}$, mitocondrias; $\mathrm{n}$, núcleo; nu, nucléolo. (Escalas: A, $2 \mu \mathrm{m} ; \mathrm{C}, 1 \mu \mathrm{m}$; B, $\mathrm{D}, \mathrm{E}, 500 \mathrm{~nm})$.

Figura 2. Micrografías electrónicas del germario de D. coccus. A. Célula nutricia con gran cantidad de ribosomas (flechas) y escaso retículo endoplásmico rugoso (rer). B. Célula nutricia con enorme cantidad de mitocondrias (flechas). C. Simbiontes (s) en célula nutricia, rodeados de una membrana perisimbiótica (flechas). D. Laminillas anulares (con ocho cisternas) en célula nutricia. E. Cordón trófico con enorme cantidad de ribosomas (cuadro), mitocondrias (m) y microtúbulos (flechas). m, mitocondria; n, núcleo. (Escala: A-E, 500 $\mathrm{nm})$.
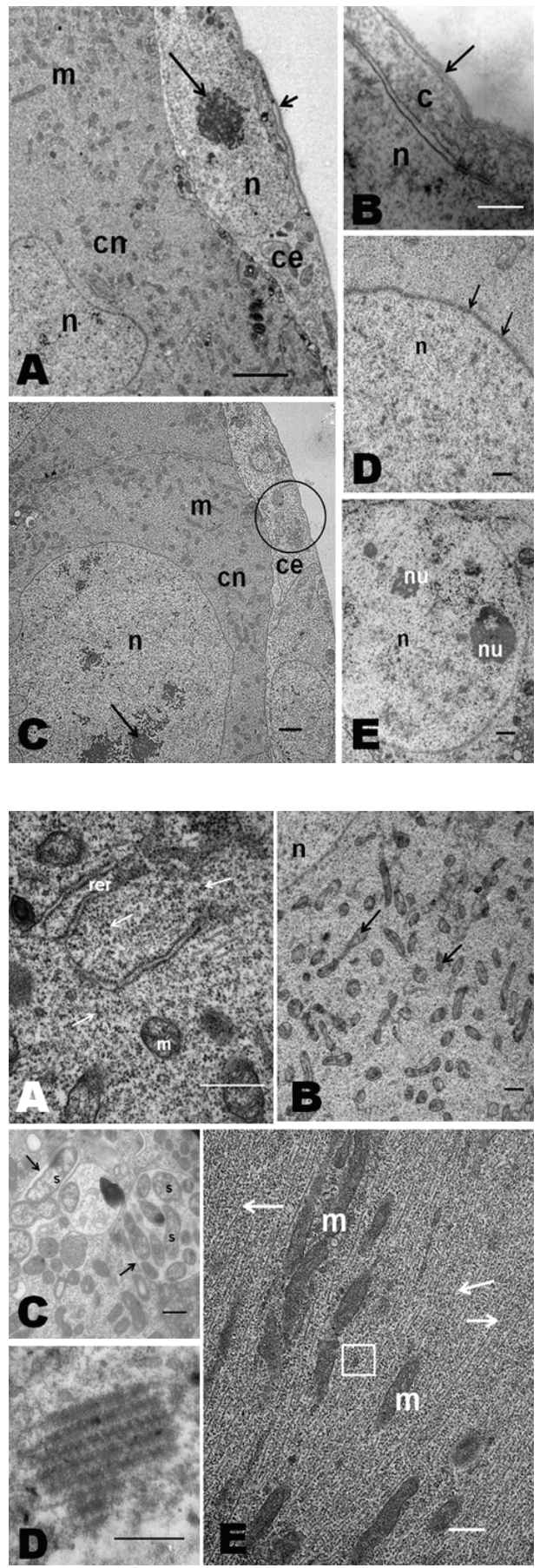
fico, además de una enorme cantidad de ribosomas dispersos entre los microtúbulos (Fig. 2E).

\section{DISCUSIÓN}

Aunque por microscopía de luz Ramírez-Cruz et al. (2008) indicaron la presencia de una cubierta epitelial rodeando el germario de $D$. coccus, no señalaron la existencia de otras cubiertas adicionales a ella. En el presente trabajo, ultraestructuralmente se observó la presencia de dicha cubierta epitelial — que corresponde a la cubierta epitelial interna en los ovarios telotróficos (King \& Büning 1985) - rodeando al germario de $D$. coccus, además de la presencia de una túnica propia externa. En este mismo sentido, en los coccoideos Newsteadia floccosa (De Geer) y Orthezia urticae (L.) (Szklarzewicz 1997) y en Palaeococcus fuscipennis (Burmeister) (Szklarzewicz et al. 2005), aunque se indica que su germario también presenta una cubierta epitelial interna, no se menciona la existencia de una cubierta externa adicional a ésta.

La alta densidad de poros nucleares en los núcleos de las células nutricias de $D$. coccus, se puede observar con frecuencia en los núcleos de células poliploides que no están dividiéndose y que muestran además una alta actividad nuclear (Maul \& Deaven 1977). Esta alta densidad de poros nucleares en las células nutricias, también se ha observado en otras especies de Coccoidea como en el caso de Aspidiotus hederae Bouche (Ksiazkiewicz 1980), Dysmicoccus newsteadi Green, Kermes quercus Linnaeus, Eriococcus buxi Fonsolombe, Gossyparia spuria Modeer, Cryptococcus fagisuga Lindiger, Pseudochermes fraxini Kaltenbach (Szklarzewicz 1998a), Porphyrophora polonica (L.) (Szklarzewicz 1998b) y en P. fuscipennis (Szklarzewicz et al. 2005).

La abundancia de ribosomas y mitocondrias en las células nutricias de D. coccus, es característica también de las células nutricias en otros Coccoidea (Ksiazkiewicz 1980; Szklarzewicz 1998a; Szklarzewicz 1998b; Koteja et al. 2003; Szklarzewicz et al. 2005). Con relación al escaso retículo endoplásmico rugoso, así como la ausencia total de retículo endoplásmico liso y de complejos de Golgi en dichas células de $D$. coccus, es conocido que en general el citoplasma de las células nutricias en Hemiptera presentan una muy alta concentración de ribonucleoproteínas y mitocondrias, mientras que los organelos membranosos tales como el retículo endoplásmico rugoso y los complejos de Golgi son raros (Telfer 1965; King \& Büning 1985). La presencia de escaso retículo endoplásmico rugoso en las células nutricias de $D$. coccus, indicó cierta actividad sintética de proteínas realizada por estas células, proteínas que podrían ser enviadas hacia el ovocito en el vitelario, tal como sucede en el caso de Dysdercus intermedius Distant (Pyrrhocoridae) (Biczkowski \& Dittmann 1995).

Con relación a los simbiontes hallados en las células nutricias de D. coccus, se desconoce el grupo taxonómico al que pertenecen y aunque recientemente Ramírez- 
Puebla et al. (2010) han identificado a una $\beta$ proteobacteria como endosimbionte tanto en huevos como en bacteriocitos de D. coccus, es necesario profundizar en los estudios a este respecto. La posible función de estos simbiontes en la fisiología del ovario de $D$. coccus, también quedaría por determinarse, aunque no se debe descartar la posibilidad de su participación en la síntesis del ácido carmínico, ya que varios policétidos (entre ellos las quinonas) producidos en los insectos (por ejemplo en Galerucini, Coleoptera) son sintetizados por endosimbiontes (Pankewitz \& Hilker 2008). Aunque los simbiontes hallados en las células nutricias de $D$. coccus, estuvieron rodeados de una membrana perisimbiótica, en Coccoidea se han reportado simbiontes presentes en el citoplasma de las células nutricias de A. hederae (Ksiazkiewicz 1980), en el citoplasma de células nutricias y de ovocitos de Steingelia gorodetskia Nassonov (Koteja et al. 2003) y en el citoplasma de los ovocitos de ninfas de P. polonica (Szklarzewicz 1998b), pero no se señala en estos casos que estén rodeados de una membrana perisimbiótica.

Se desconoce la posible función de las laminillas anulares de las células nutricias en los germarios de las hembras de 10 días de D. coccus; en este caso pudieran estar relacionadas con el proceso de degeneración que sufren dichas células después de esta edad (datos no publicados), aunque es necesario profundizar en el estudio de estas estructuras para dar conclusiones definitivas. Las laminillas anulares se han observado de manera normal en las células germinales de diferentes grupos animales, y su hallazgo en células somáticas de diversos tejidos se ha asociado a una gran cantidad de factores, tanto normales como patológicos (Kessel 1992). En el coccoideo $S$. gorodetskia se han observado laminillas anulares cercanas al núcleo y asociadas al retículo endoplásmico rugoso, sin atribuírseles alguna posible función (Koteja et al. 2003).

Ultraestructuralmente, con relación a la presencia de microtúbulos, mitocondrias y ribosomas en los cordones tróficos de D. coccus, las características fueron básicamente semejantes a las observadas en otras especies de coccoideos estudiadas (Ksiazkiewicz 1980; Szklarzewicz 1998a; 1998b; Koteja et al. 2003; Szklarzewicz et al. 2005) y en general a hemípteros (King \& Büning 1985). Sin embargo, en particular en el suborden Psyllina, los cordones tróficos no presentan microtúbulos (Büning 1993). En vista de que los microtúbulos son necesarios para el mantenimiento de la estructura del cordón trófico, el transporte de organelos y de RNA hacia los ovocitos, así como para regular el tipo y tamaño de los organelos que atraviesan el cordón trófico (MacGregor \& Stebbings 1970; Stebbings et al. 1995), sería importante conocer cómo se suplen estas funciones en los cordones tróficos de Psyllina sin la presencia de microtúbulos.

Agradecimientos. A la Dra. Celina Llanderal, del Colegio de Postgraduados, Campus Montecillo, por haber proporcionado las hembras de D. coccus usadas como pie de cría. Al personal de la Central 
de Microscopía de la Escuela Nacional de Ciencias Biológicas del Instituto Politécnico Nacional: M. en C. María Esther Sánchez E. y Dr. Oliver López V., por su asesoría en el procesamiento del material biológico así como en el manejo del microscopio electrónico de transmisión. Al Dr. Samuel Pineda de la UMSNH, por sus comentarios sobre el escrito original. A los revisores anónimos por sus valiosas aportaciones para mejorar el escrito final.

\section{LITERATURA CITADA}

Aldama A. C. \& Llanderal, C. 2003. Grana cochinilla: comparación de métodos de producción en penca cortada. Agrociencia, 37: 11-19.

Biczkowski, M. \& Dittmann, F. 1995.Translation of maternal mRNA during early oogenesis in a telotrophic-meroistic insect (Dysdercus intermedius). Journal of Insect Physiology, 41: 1133-1139.

Büning, J. 1993. Germ cell cluster formation in insect ovaries. International Journal of Insect Morphology and Embryology, 22: 237-253.

Cortés, D., Vigueras, A. L. \& Portillo, L. 2005. Relación del aparato reproductor femenino de Dactylopius coccus Costa (Hemiptera: Dactylopiidae) en la síntesis del ácido carmínico. Scientia-Cucba, 7: 131-138.

Engelmann, F. 1970. The Physiology of Insect Reproduction. Pergamon Press, Oxford.

Kessel, R. G. 1992. Annulate lamellae: a last frontier in cellular organelles. International Review of Citology, 133: 43-120.

King, R. C. \& Büning, J. 1985. The origin and functioning of insects oocytes and nurse cells. Pp. $37-$ 82. In: G. A. Kerkut and L. I. Gilbert. (Eds.). Comprensive Insects Physiology, Biochemistry and Pharmacology. Pergamon Press, New York.

Koteja, J., Pyka-Fosciak, G., Vogelgesang, M. \& Szklarzewicz, T. 2003. Structure of the ovary in Steingelia (Sternorrhyncha: Coccinea) and its phylogenetic implications. Arthropod Structure and Development, 32: 247-256.

Ksiazkiewicz, M. 1980. Ultrastructure of the trophic chamber and nutritive cord of Aspidiotus hederae (Homoptera, Coccoidea). Cell and Tissue Research, 213: 149-157.

MacGregor, H. C. \& Stebbings, H. 1970. A massive system of microtubules associated with cytoplasmic movement in telotrophic ovarioles. Journal of Cell Science, 6: 431-449.

Martínez M., I. 1999. Estudio de la anatomía microscópica en insectos: Técnicas básicas. Folia Entomológica Mexicana, 105: 65-76.

Maul, G. G. \& Deaven, L. 1977. Quantitative determination of nuclear pore complex in cycling cells with differing DNA content. The Journal of Cell Biology, 73: 748-760.

Pankewitz, F. \& Hilker, M. 2008. Poliketides in insects: ecological role of these widespread chemicals and evolutionary aspects of their biogenesis. Biological Reviews, 83: 209-226.

Ramírez-Cruz, A., Llanderal-Cázares, C. \& Racotta, R. 2008. Ovariole structure of cochineal scale insect, Dactylopius coccus. 5 pp. Journal of Insect Science. 8: 20. insectscience.org/8.20.

Ramírez-Puebla, S. T., Rosenblueth, M., Chávez-Moreno, C. K., Catanho Pereira de Lyra, M. C., Tecante, A. \& Martínez-Romero, E. 2010. Molecular phylogeny of the genus Dactylopius (Hemiptera: Dactylopiidae) and identification of the symbiotic bacteria. Environment Entomology, 39: 1178-1183.

Stebbings, H., Lane, J. D. \& Talbot, N. J. 1995. mRNA translocation and microtubules: insect ovary models. Trends in Cell Biology, 5: 361-365.

Szklarzewicz, T. 1997. Structure and development of the telotrophic ovariole in ensing scale insects (Hemiptera, Coccomorpha: Ortheziidae). Tissue and Cell, 29: 31-38. 
Szklarzewicz, T. 1998a. Structure of ovaries in scale insects. I. Pseudococcidae, Kermesidae, Eriococcidae and Cryptococcidae (Insecta, Hemiptera, Coccinea). International Journal of Insect Morphology and Embryology, 27: 167-172.

Szklarzewicz, T. 1998b. Structure of ovaries of scale insects: II. Margarodidae (Insecta, Hemiptera, Coccinea). International Journal of Insect Morphology and Embryology, 27: 319-324.

Szklarzewicz, T., Kedra, K. \& Niznik, S. 2005. Ultrastructural studies of the ovary of Palaeococcus fuscipennis (Burmeister) (Insecta, Coccinea: Monophlebidae). Folia Biologica (Kraków), 53: 4551.

Telfer, W. H. 1965. The mechanism and control of yolk formation. Annual Review of Entomology, 10: 161-184.

Vigueras, A. L. \& Portillo, L. 2001. Usos del pigmento de la grana cochinilla. Pp. 93-103. In: C. Llanderal y R. Nieto H. (Eds.). Producción de grana cochinilla. Colegio de Postgraduados, Montecillo, México. 